\title{
Evolução das bolsas de produtividade em pesquisa e dos editais universais do CNPq no Programa Básico de Zootecnia: 2002 a 2006
}

\section{Maria Auxiliadora da Silveira e Pereira Neves'; Roberto Camargos Antunes²; Emerson Silva Ribeiro Júnior ${ }^{2}$; Cláudia Queiroz Gorgati ${ }^{3}$}

\author{
1 - Diretora Substituta da Diretoria de Programas Temáticos e Setoriais / Coordenadora da Coordenação Geral dos Programas \\ de Pesquisa do Agronegócio e da Biotecnologia - DPT/CGAPB/CNPq; \\ 2 - Analista em Ciência e Tecnologia da Coordenação dos Programas de Pesquisa em Agropecuária e do Agronegócio - COAGR/ \\ CNPq; \\ 3 - Coordenadora da Coordenação dos Programas de Pesquisa em Agropecuária e do Agronegócio - COAGR/CNPq.
}

\section{Introdução}

Criado pela Lei $\mathrm{n}^{\circ} 1.310$ de 15 de janeiro de 1951, o Conselho Nacional de Desenvolvimento Científico e Tecnológico (CNPq) é uma Fundação vinculada ao Ministério da Ciência e Tecnologia (MCT) para o apoio à pesquisa brasileira. Contribuindo diretamente para a formação de pesquisadores (mestres, doutores e especialistas em várias áreas de conhecimento), o CNPq é, desde sua criação até hoje, uma das maiores e mais sólidas estruturas públicas de apoio à Ciência, Tecnologia e Inovação (CT\&I) dos países em desenvolvimento.

A história do $\mathrm{CNPq}^{1}$ está associada ao desenvolvimento e institucionalização da ciência e tecnologia no Brasil. À sua trajetória se vinculam os mais expressivos cientistas e pesquisadores brasileiros.

Os investimentos feitos pelo CNPq são direcionados para a formação e absorção de recursos humanos e financiamento de projetos de pesquisa, que contribuem para o aumento da produção de conhecimento e geração de novas oportunidades de crescimento para o País.

Como parte da política em $\mathrm{C} \& \mathrm{~T}$, o $\mathrm{CNPq}$ convida periodicamente os pesquisadores e/ou

\footnotetext{
${ }^{1}$ Maiores informações sobre a história deste Conselho, bem como bibliografia disponível, consultar o Centro de Memória do CNPq no endereço http://centrode memoria.cnpq.br/index.html.
}

grupos de pesquisas interessados a apresentar propostas para concorrer à bolsa de produtividade em pesquisa - Pq, por meio de chamada específica, e/ou para concorrer ao auxílio financeiro à pesquisa, via Edital Universal, além de diversas outras formas de fomento à pesquisa científica $\mathrm{e}$ tecnológica disponibilizadas.

A finalidade da concessão da bolsa Pq é distinguir o pesquisador com elevada produção, valorizando sua produção acadêmica segundo critérios normativos, estabelecidos pelo CNPq, e específicos, pelos Comitês de Assessoramento CA's. A bolsa é concedida individualmente, em função do mérito da proposta, ao pesquisador que satisfaça os pré-requisitos estabelecidos pelo $\mathrm{CNPq}$ e aos critérios de qualificação definidos pelos Comitês de Assessoramento de cada área ou pelo Conselho Deliberativo do CNPq, no caso de Pesquisador Sênior. Os critérios adotados pelos CA's para atender às solicitações de bolsa Pq são revistos a cada 3 (três) anos e divulgados na página eletrônica do CNPq no endereço http://www.cnpq.br/cas/ criterios.htm, podendo, excepcionalmente, serem alterados a critério do Comitê Assessor e do CNPq.

O Edital Universal tem como característica representar a demanda espontânea pela pesquisa das Universidades e dos Centros de Pesquisa, uma vez que é aberto aos pesquisadores doutores e a todo tipo de proposta de pesquisa de todas as áreas do conhecimento. Tem como objetivo estimular a produção científica/tecnológica e financiar a

Correspondências devem ser enviadas para: Conselho Nacional de Desenvolvimento Científico e Tecnológico

Coordenação Geral dos Programas de Pesquisa e Agropecuária e Biotecnologia - CGAPB

SEPN 509, Bloco “A”, Ed. Nazir I - 70.750-510,Brasília, DF .E-mail: cgapb@cnpq.br 
execução de projetos de pesquisa, desenvolvimento e inovação, apresentados por pesquisadores, que representem contribuição significativa para o desenvolvimento científico e tecnológico do País.

A Coordenação Geral do Programa de Pesquisa em Agropecuária e Biotecnologia - CGAPB é uma das três coordenações gerais vinculadas à Diretoria de Programas Temáticos e Setoriais do CNPq. A CGAPB reúne a Coordenação dos Programas de Pesquisa em Biotecnologia e Recursos Genéticos - COBRG e a Coordenação de Programas de Pesquisa em Agropecuária e Agronegócio COAGR. A COAGR reúne sete Programas Científicos Básicos (Agronomia, Aquicultura e Recursos Pesqueiros, Ciência e Tecnologia de Alimentos, Engenharia Agrícola, Medicina Veterinária, Recursos Florestais e Engenharia Florestal e Zootecnia), que estão inseridos dentro da área do conhecimento de Ciências Agrárias.

Cada Programa Básico possui um Comitê Assessor correspondente, formado por pesquisadores de notória distinção científica junto à Comunidade Científica. O Comitê Assessor é responsável pelo julgamento do mérito científico e também pela recomendação das propostas apresentadas aos Editais Universais e às chamadas de bolsas Pq à Diretoria do CNPq. Cabe à Diretoria a decisão final sobre as concessões dos recursos financeiros ou de bolsa Pq.

O Programa Básico de Zootecnia é composto por cinco subáreas do conhecimento, sendo que três delas são desmembradas em especialidades, conforme pode ser visto no Esquema 1. Em maio de 2006, por decisão do Conselho Deliberativo do CNPq, o Programa Básico de Zootecnia passou a contar com Comitê Assessor próprio, o CA-ZT, sendo criado a partir do desmembramento do antigo Comitê Assessor de Medicina Veterinária e Zootecnia - CA-VT.

\section{Objetivo}

Esse trabalho analisa a evolução das subáreas do conhecimento e de suas respectivas especialidades do Programa Básico de Zootecnia do CNPq nas últimas quatro chamadas de bolsas de Produtividade em Pesquisa e nos últimos três Editais Universais.

\section{Metodologia}

Esse estudo avaliou a evolução da demanda bruta (número total de propostas submetidas em um edital ou chamada) e da demanda atendida dos três Editais Universais e das quatro últimas chamadas de bolsas Pq nas cinco subáreas do conhecimento e nas respectivas especialidades do Programa Básico de Zootecnia em atividade no CNPq.

Os três Editais Universais e as quatro chamadas de bolsas $\mathrm{Pq}$ analisados nesse estudo são apresentados na Tabela 1. Dessa forma, foi possível

\author{
Ciências Agrárias \\ Zootecnia \\ Ecologia dos Animais Domésticos e Etologia \\ Genética e Melhoramento dos Animais Domésticos \\ Nutrição e Alimentação Animal \\ Avaliação de Alimentos para os Animais Domésticos \\ Conservação de Alimentos para Animais \\ Exigências Nutricionais dos Animais \\ Pastagem e Forragicultura \\ Avaliação, Produção e Conservação de Forragens \\ Fisiologia de Plantas Forrageiras \\ Manejo e Conservação de Pastagens \\ Melhoramento de Plantas Forrageiras e Produção de Sementes \\ Toxicologia e Plantas Tóxicas \\ Produção Animal \\ Criação de Animais \\ Instalações para a Produção Animal \\ Manejo de Animais
}

\footnotetext{
Esquema 1 - Estrutura da árvore do conhecimento do Programa Básico de Zootecnia do CNPq disponível em http://www.cnpq.br/areasconhecimento/5.htm

๑ 2007 Sociedade Brasileira de Zootecnia
} 
Tabela 1 - Relação de chamadas de bolsas Pq e de Editais Universais lançados pelo CNPq no período de 2002 a 2006.

\begin{tabular}{cclc}
\hline Chamadas de Bolsas Pq & Vigência $^{1}$ & Editais Universais & Vigência $^{1}$ \\
\hline CA 10/2003 & $2004-2007$ & Edital CNPq N. $^{\mathbf{0}}$ 01/2002 & $2003-2005$ \\
CA 10/2004 & $2005-2008$ & Edital CNPq N. $^{\mathbf{1}}$ 19/2004 & $2005-2007$ \\
CA 10/2005 & $2006-2009$ & Edital CNPq N. $^{\mathbf{0}}$ 02/2006 & $2007-2009$ \\
CA 10/2006 & $2007-2010$ & & \\
\hline
\end{tabular}

${ }^{1}$ Vigência aproximada, não levando em consideração os processos que tiveram prorrogação do período de vigência. Foi considerado a vigência de 36 meses para todas as bolsas Pq e de 24 meses para todos os Auxílios à Pesquisa concedidos no âmbito dos Editais Universais.

acompanhar a evolução das subáreas em atividade do Programa Básico de Zootecnia a partir de 2002 para os Editais Universais e de 2003 para as chamadas de bolsas Pq.

Os dados consolidados de demandas bruta e atendida para as quatro chamadas de bolsas $\mathrm{Pq}$ e dos três Editais Universais foram obtidos por meio de consultas aos bancos de dados Oracle do CNPq, utilizando a ferramenta de busca PL-SQL, pela Coordenação de Suporte ao Fomento - COSFO. Os dados foram submetidos a análises de média aritmética e de correlação.

\section{Resultados e Discussão}

\section{Produtividade em Pesquisa - Pq}

A especialidade Toxicologia e Plantas Tóxicas apresentou apenas uma proposta nas quatro últimas chamadas de bolsa $\mathrm{Pq}$, no período estudado. Isto parece indicar baixo interesse para esta subárea ou inadequada subdivisão da subárea no Programa Básico de Zootecnia. Os pesquisadores interessados em submeter a proposta na especialidade Toxicologia e Plantas Tóxicas parecem optar por submeter as solicitações para a especialidade Toxicologia Animal do Programa Básico de Medicina Veterinária (CA-VT), que neste período apresentou demanda bruta de 13 propostas de bolsa Pq e 8 propostas de Auxílio à Pesquisa via Editais Universais. Sendo assim, diante da baixa demanda optou-se por não inserila nas discussões seguintes.

Observou-se aumento na demanda bruta de solicitações de bolsas Pq no último ano (Figura 1), atingindo em 2006 valor próximo ao encontrado em 2003.

Observa-se também um grande aumento no percentual de atendimento à demanda bruta apresentada no ano de 2006, variando de 37,4, $46,3,31,1$ e $55,4 \%$ no período em estudo. Isto é fruto do esforço do $\mathrm{CNPq}$ nos últimos anos no sentido de incrementar os recursos destinados a $\mathrm{C} \& \mathrm{~T}$, disponibilizando-os às propostas meritórias.

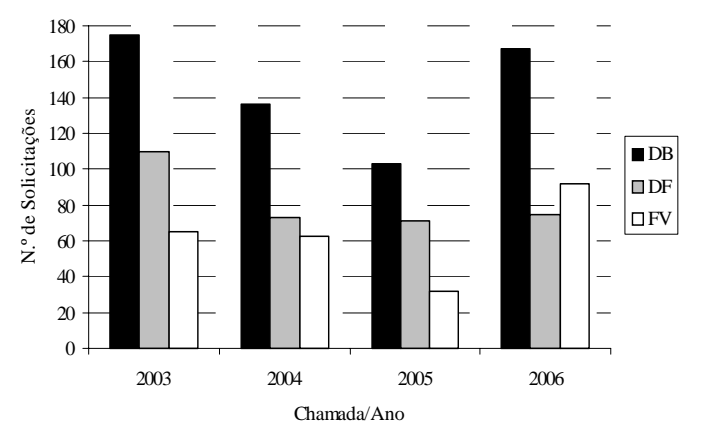

Figura 1 - Evolução da demanda bruta (DB), dos projetos não apoiados (DF) e da demanda atendida (FV) pelo CNPq para os julgamentos de bolsas Pq ocorridos entre 2003 e 2006.

O CNPq modificou as normas de concessão de bolsas $\mathrm{Pq}$, eliminando o processo de renovação de bolsas. A partir de então, todas as solicitações de bolsas passaram a ser julgadas de forma independente do histórico do bolsista $\mathrm{Pq}$ no $\mathrm{CNPq}$. A classificação e o enquadramento da proposta de bolsa passaram a focar a produtividade continuada nos últimos cinco anos, de acordo com os critérios de avaliação disponibilizados em http://www. cnpq.br/cas/criterios.htm.

A prática tem mostrado que a nova forma de avaliação parece ser mais justa, pois propicia uma maior mobilidade de acesso à bolsa entre os pesquisadores da área, fortalecendo a concorrência e, por conseqüência, a Produtividade em Pesquisa, objetivo maior da ação.

\section{Evolução das subáreas}

Comparando-se a demanda bruta de todas as subáreas estudadas do Programa Básico de Zootecnia com a demanda atendida (propostas aprovadas e financiadas) para o período de 2003

๑ 2007 Sociedade Brasileira de Zootecnia 
a 2006, observou-se um estreitamento das correlações, com valores variando de $0,892,0,935$, 0,889 e 0,978 , respectivamente, para cada ano.

Estas altas correlações parecem indicar que tanto o Comitê de Assessoramento, no momento do julgamento, quanto a direção do CNPq, no momento da aprovação das propostas, parecem estar sensíveis à oscilação da demanda bruta, distribuindo as cotas de bolsas Pq segundo a solicitação espontânea de cada área. No entanto, alguns ajustes devem ser feitos, orientados por uma política distributiva segundo interesses nacionais de C\&T.

Assim, no estudo evolutivo das demandas bruta e atendida de cada subárea individualizada percebe-se que, de forma geral, Nutrição $e$ Alimentação Animal é a subárea que de forma crescente apresenta a maior demanda bruta, seguida pela Produção Animal, para as quais as percentagens de solicitações oscilaram entre 21,3 e 27,2\% no período estudado (Figura 2).

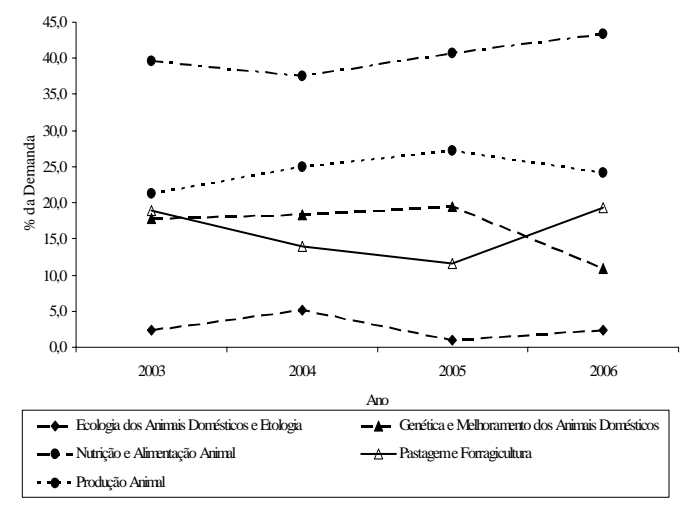

Figura 2 - Relação entre número de propostas submetidas de bolsa Pq para cada subárea e o número total de propostas submetidas (demanda bruta) para o Programa de Zootecnia.

A subárea de menor demanda bruta foi a Ecologia dos Animais Domésticos e Etologia com variações máximas de $5,1 \%$ da demanda bruta em 2004 e mínima de 1,0\% em 2005.

Em 2006, com o aumento do número de projetos submetidos por pesquisadores da área de Pastagem e Forragicultura e decréscimo de Genética e Melhoramento dos Animais Domésticos a tendência de queda e crescimento respectivamente, se inverteu com valores relativos de 19,3\% para Pastagem e Forragicultura e 10,8\% para Genética e Melhoramento dos Animais Domésticos.

๑) 2007 Sociedade Brasileira de Zootecnia
$\mathrm{O}$ atendimento às solicitações de bolsa $\mathrm{Pq}$ da chamada CA 10/2006 apresenta valores relativos semelhantes aos valores de demanda bruta, para todas as subáreas (Figura 3).

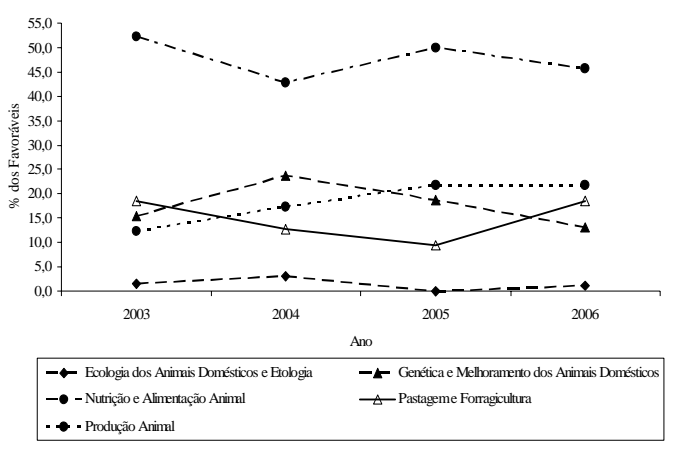

Figura 3 - Relação entre número de propostas atendidas de bolsa Pq para cada subárea e o número total de propostas atendidas para o Programa de Zootecnia.

A tendência de diminuição ao atendimento à Nutrição e Alimentação Animal fez com que em 2006 a demanda bruta $(43,4 \%)$ se assemelhasse a demanda atendida $(45,7 \%)$, diminuindo esta diferença, que chegou a ser de $12,6 \%$ no ano de 2003, favorável ao atendimento.

Semelhantemente à demanda bruta, a demanda atendida para Produção Animal apresentou um elevado crescimento no período, passando de $12,3 \%$ em 2003 para 21,7\% em 2006, destacando a importância crescente do tema.

Tanto para Pastagem e Forragicultura quanto para Genética e Melhoramento dos Animais Domésticos as curvas de tendências de atendimento às solicitações no período foram muito semelhantes às curvas de tendências de solicitação (Figuras 3 e 2 respectivamente). No entanto, para a subárea de Genética e Melhoramento dos Animais Domésticos a curva de tendência de solicitação (Figura 2) apresentou inflexão negativa da solicitação em 2005, enquanto que a inflexão negativa da curva de atendimento ocorreu um ano antes (Figura 3).

Ecologia dos Animais Domésticos e Etologia foi a subárea de menor atendimento relativo no ano de $2006(1,1 \%)$, ainda menor que sua demanda bruta $(2,4 \%)$ para o mesmo ano. Isto parece refletir o pouco interesse e incentivo da comunidade acadêmica com o tema.

No entanto, as subáreas Nutrição e Alimentação Animal, Pastagem e Forragicultura e 
Produção Animal são, de acordo com a árvore de conhecimento do CNPq, subdivididas em especialidades, com número variável conforme a subárea (Tabelas 1 e 2).

Nutrição e Alimentação Animal é dividida em quatro diferentes especialidades. Destas destaca-se negativamente Conservação de Alimentos para Animais, que apresentou nos últimos quatro anos uma baixa e decrescente demanda bruta de bolsa Pq, com propostas financiadas apenas no ano de 2005.

Por outro lado, Exigências Nutricionais dos Animais e Avaliação de Alimentos para Animais apresentaram no período número proporcionalmente maior de propostas financiadas comparativamente às suas demandas brutas, refletindo a qualidade/quantidade da produção científica das especialidades e a avaliação do CA.

As diferentes especialidades da Pastagem $e$ Forragicultura apresentaram valores relativos baixos, tanto de demanda bruta como de demanda atendida, denotando limitações de interesse pela comunidade acadêmica. Destacam-se as especialidades Pastagem e Forragicultura e Avaliação e Conservação de Pastagem, com valores de submissão e aprovação com pequena variação e próximos a $5 \%$ ao longo dos anos.
Dentro da subárea Produção Animal destacase a especialidade de mesmo nome, com demanda bruta variando de 11,5 a 18,4\% no período, porém com demanda atendida ligeiramente menor, variando de 6,3 a 16,3\%. Instalações para Produção Animal apresentou número muito baixo de solicitações, não tendo nenhuma proposta atendida.

\section{Edital Universal}

Avaliando a demanda dos Editais Universais 01/2002, 019/2004 e 02/2006, observa-se um aumento no número de projetos submetidos ao Programa Básico de Zootecnia, passando de cerca de 190 em 2002 para próximo a 320 propostas nas duas últimas chamadas, como pode ser visto na Figura 4.

Percebe-se que tanto em 2002 quanto em 2006 apenas $15 \%$ dos projetos submetidos foram aprovados e financiados pelo CNPq. No entanto, em 2004, a porcentagem de projetos aprovados mais que dobrou em relação aos outros anos $(33,2 \%)$. Isto deveu-se ao apoio financeiro adicional recebido do Fundo Setorial do Agronegócio para fomentar projetos de pesquisas meritórios no âmbito da Coordenação do Programa

Tabela 2 - Evolução percentual da demanda bruta e da demanda atendida de bolsas Pq nas subáreas do Programa Básico de Zootecnia.

\begin{tabular}{|c|c|c|c|c|c|c|c|c|}
\hline \multirow[b]{2}{*}{ Subáreas } & \multicolumn{4}{|c|}{ Demanda Bruta (\%) } & \multicolumn{4}{|c|}{ Demanda Atendida (\%) } \\
\hline & 2003 & 2004 & 2005 & 2006 & 2003 & 2004 & 2005 & 2006 \\
\hline \multicolumn{9}{|l|}{ Nutrição e Alimentação Animal } \\
\hline Conservação de Alimentos para Animais & 2,3 & 1,5 & 1,0 & 0,0 & 0,0 & 0,0 & 3,1 & 0,0 \\
\hline Exigências Nutricionais dos Animais & 8,6 & 5,9 & 6,8 & 7,2 & 13,8 & 6,3 & 15,6 & 8,7 \\
\hline Avaliação de Alimentos para Animais & 17,2 & 15,4 & 10,7 & 15,7 & 27,7 & 17,5 & 15,6 & 15,2 \\
\hline Nutrição e Alimentação Animal & 11,5 & 14,7 & 22,3 & 20,5 & 10,8 & 19,0 & 15,6 & 21,7 \\
\hline Sub-total & 39,7 & $\mathbf{3 7 , 5}$ & 40,8 & 43,4 & 52,3 & 42,9 & $\mathbf{5 0 , 0}$ & 45,7 \\
\hline \multicolumn{9}{|l|}{ Pastagem e Forragicultura } \\
\hline Fisiologia de Plantas Forrageiras & 0,6 & 1,5 & 0,0 & 2,4 & 1,5 & 1,6 & 0,0 & 3,3 \\
\hline Manejo e Conservação de Pastagens & 2,9 & 1,5 & 2,9 & 1,8 & 3,1 & 0,0 & 3,1 & 3,3 \\
\hline Melhor. de Plantas Forrag. e Prod. de Sementes & s 3,4 & 2,9 & 1,0 & 2,4 & 1,5 & 3,2 & 0,0 & 3,3 \\
\hline Pastagem e Forragicultura & 6,9 & 2,2 & 2,9 & 7,2 & 7,7 & 3,2 & 3,1 & 4,3 \\
\hline Avaliação e Conservação de Forragens & 5,2 & 5,9 & 4,9 & 5,4 & 4,6 & 4,8 & 3,1 & 4,3 \\
\hline Sub-total & 19,0 & 14,0 & 11,7 & 19,3 & 18,5 & 12,7 & $\mathbf{9 , 4}$ & 18,5 \\
\hline \multicolumn{9}{|l|}{ Produção Animal } \\
\hline Instalações para Produção Animal & 0,6 & 0,0 & 0,0 & 0,6 & 0,0 & 0,0 & 0,0 & 0,0 \\
\hline Manejo de Animais & 6,9 & 4,4 & 3,9 & 1,8 & 3,1 & 6,3 & 3,1 & 2,2 \\
\hline Criação de Animais & 2,3 & 8,8 & 4,9 & 3,6 & 1,5 & 4,8 & 3,1 & 3,3 \\
\hline Produção Animal & 11,5 & 11,8 & 18,4 & 18,1 & 7,7 & 6,3 & 15,6 & 16,3 \\
\hline Sub-total & 21,3 & 25,0 & 27,2 & 24,1 & 12,3 & 17,5 & 21,9 & 21,7 \\
\hline Ecologia dos Animais Domésticos e Etologia & 2,9 & $\mathbf{1 , 5}$ & 2,9 & 1,8 & 3,1 & $\mathbf{0 , 0}$ & 3,1 & $\mathbf{3 , 3}$ \\
\hline Genética e Melhor. dos Animais Domésticos & 17,8 & 18,4 & 19,4 & 10,8 & 15,4 & 23,8 & 18,8 & 13,0 \\
\hline Totat geral & 100 & 100 & 100 & 100 & 100 & 100 & 100 & 100 \\
\hline
\end{tabular}

๑ 2007 Sociedade Brasileira de Zootecnia 
de Pesquisa em Agropecuária e Agronegócio COAGR, permitindo que mais propostas da área de Zootecnia fossem financiadas.

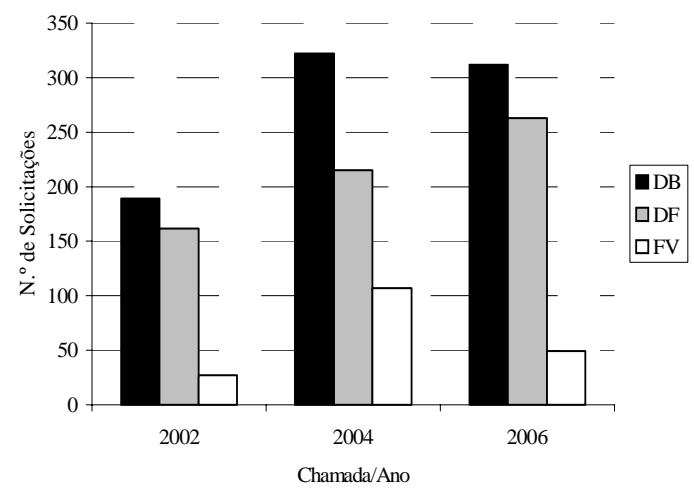

Figura 4 - Evolução da demanda bruta (DB), dos projetos não apoiados (DF) e demanda atendida (FV) pelo $\mathrm{CNPq}$ para os julgamentos dos Editais Universais 01/2002, 019/2004 e 02/ 2006.

Semelhantemente às bolsas $\mathrm{Pq}$, as correlações entre o número de propostas submetidas por subárea e o número de propostas aprovadas estreitou-se com as chamadas mais recentes, passando de 0,737, 0,884 a 0,909 em 2002, 2004 e 2006, respectivamente. Essas elevadas correlações ratificam o fato de, mesmo não constando como critério expresso do Comitê de Assessoramento, o atendimento às diferentes subáreas guarda relação com suas respectivas demandas brutas.

\section{Evolução das subáreas}

Observa-se na Figura 5, de forma geral, que as variações relativas do número de propostas submetidas nas diferentes subáreas da zootecnia foram bastante pequenas.

Importante destacar que em 2006 os valores relativos de demanda bruta do Edital Universal e da bolsa Pq foram de magnitude semelhante, implicando num mesmo ordenamento quantitativo das subáreas para as duas chamadas, sendo Nutrição e Alimentação Animal a que submeteu o maior número de propostas e Ecologia dos Animais Domésticos e Etologia o menor.

Nutrição e Alimentação Animal apresentou ao longo dos 3 últimos editais uma ligeira queda no número de projetos, caindo de 39,2\% em 2002 para $36,0 \%$ em 2006. O mesmo se repetiu para Ecologia dos Animais Domésticos e Etologia, caindo de 4,8 para $1,9 \%$.

๑) 2007 Sociedade Brasileira de Zootecnia
Pastagem e Forragicultura e Genética e Melhoramento dos Animais Domésticos oscilaram muito pouco, 0,5 e $0,7 \%$ respectivamente, sendo que a demanda da subárea Produção Animal aumentou $4 \%$ passando de 20,6 para $24,6 \%$ em relação ao total da área no período estudado.

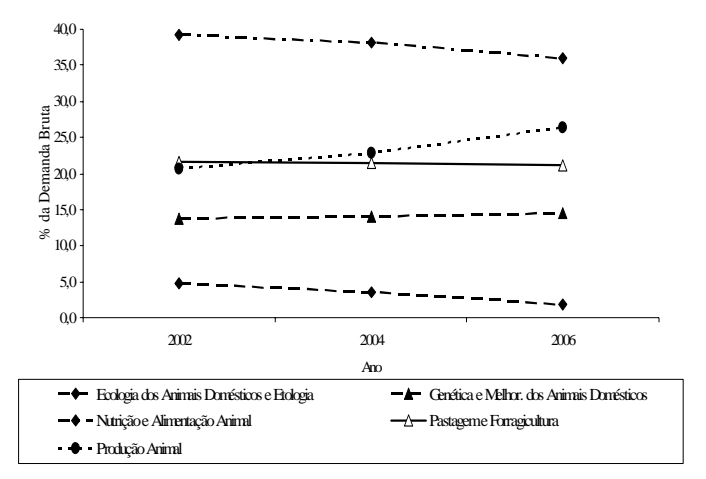

Figura 5 - Relação entre número de propostas submetidas aos Editais Universais para cada subárea e o número total de propostas submetidas (demanda bruta) para o Programa de Zootecnia.

Embora a ordenação dos projetos aprovados tenha sido a mesma da demanda bruta (Figura 6) para o ano de 2006, os valores percentuais relativos para os projetos aprovados quando comparados com a demanda bruta, principalmente para Nutrição e Alimentação Animal foram bastantes diferentes no período estudado.

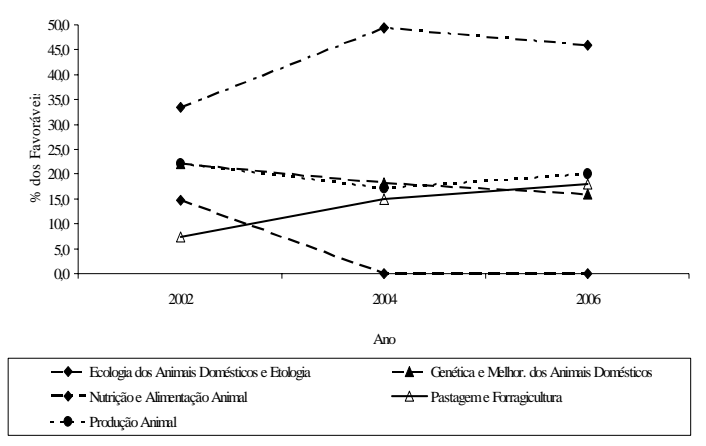

Figura 6 - Relação entre número de propostas financiadas (demanda atendida) para cada subárea e o número total de propostas financiadas para o Programa de Zootecnia.

Enquanto Nutrição e Alimentação Animal respondia por $33,3 \%$ da totalidade dos projetos aprovados em 2002, frente a uma demanda de $39,2 \%$, em 2004 passou a responder por $49,5 \%$ (demanda bruta de $38,1 \%$ ) e $46,0 \%$ com demanda de $36 \%$ em 2006. 
Outra subárea que apresentou um maior número relativo de projetos aprovados em relação à sua demanda bruta foi Genética e Melhoramento dos Animais Domésticos. No entanto, estudando a evolução dos percentuais relativos da demanda bruta e da demanda atendida no período, verificase que ano a ano estes dois valores se aproximaram em torno de $15 \%$ do total da área.

Destaca-se no período o crescimento da aprovação relativa para a subárea Pastagem $e$ Forragicultura, passando de 7,4\% em 2002 para $18,0 \%$ em 2006, ligeiramente abaixo de sua demanda bruta para o último ano.

Dentro da subárea Nutrição e Alimentação Animal, a especialidade que apresentou maior demanda bruta e que mais teve projetos aprovados foi Avaliação de Alimentos para Animais (Tabela 3 ), com demanda bruta variando no período de 14,3 a $19,2 \%$ e demanda qualificada de 14,8 a $20,4 \%$.

A especialidade menos apoiada foi Conservação de Alimentos para Animais, não tendo nenhum projeto aprovado nos três últimos editais.

Exigências Nutricionais dos Animais e Nutrição e Alimentação Animal foram as especialidades que apresentaram maior crescimento em número de projetos financiados, com demanda bruta quase constante.

Na subárea Pastagem e Forragicultura a especialidade com maior demanda bruta foi Avaliação e Conservação de Pastagem. Para esta especialidade observa-se tendência a recuperação da demanda atendida, pois em 2002 não teve nenhum projeto aprovado contra uma demanda bruta de $8,5 \%$ e em 2006 apresentou demanda atendida de $8 \%$ contra uma demanda bruta de $7,4 \%$.

A especialidade menos apoiada foi Fisiologia de Plantas Forrageiras, que apresentou também o menor número de projetos para avaliação.

Observa-se uma redução relativa da aprovação de projetos da especialidade Pastagem e Forragicultura nos dois últimos editais, passando de $7,4 \%$ em relação ao total aprovado na área em 2002, para apenas 2\% em 2006.

Instalações para Produção Animal parece ser uma especialidade da subárea Produção Animal de baixo interesse pela comunidade científica da Zootecnia, uma vez que tem enviado muito poucos projetos para concorrer ao financiamento do Edital Universal. Este mesmo desinteresse parece se refletir no Manejo de Animais, que apresentou demanda bruta e número de propostas financiadas

Tabela 3 - Evolução percentual da demanda bruta e da demanda atendida nos Editais Universais 01/ 2002, 019/2004 e 02/2006 nas subáreas do Programa Básico de Zootecnia.

\begin{tabular}{|c|c|c|c|c|c|c|}
\hline \multirow[b]{2}{*}{ Subáreas } & \multicolumn{3}{|c|}{ Demanda Bruta (\%) } & \multicolumn{3}{|c|}{ Demanda Atendida (\%) } \\
\hline & 2002 & 2004 & 2006 & 2002 & 2004 & 2006 \\
\hline \multicolumn{7}{|l|}{ Nutrição e Alimentação Animal } \\
\hline Conservação de Alimentos para Animais & 2,1 & 1,6 & 0,3 & 0,0 & 0,0 & 0,0 \\
\hline Exigências Nutricionais dos Animais & 7,9 & 8,1 & 6,4 & 7,4 & 12,9 & 12,0 \\
\hline Avaliação de Alimentos para Animais & 14,3 & 19,2 & 15,4 & 14,8 & 20,4 & 16,0 \\
\hline Nutrição e Alimentação Animal & 14,8 & 9,1 & 13,8 & 11,1 & 16,1 & 18,0 \\
\hline Sub-total & 39,2 & 38,1 & 36,0 & 33,3 & 49,5 & 46,0 \\
\hline \multicolumn{7}{|l|}{ Pastagem e Forragicultura } \\
\hline Fisiologia de Plantas Forrageiras & 1,6 & 2,6 & 1,6 & 0,0 & 2,2 & 0,0 \\
\hline Manejo e Conservação de Pastagens & 1,6 & 4,9 & 2,9 & 0,0 & 4,3 & 6,0 \\
\hline Melhor. de Plantas Forrag. e Prod. De Sementes & s 2,1 & 2,3 & 2,6 & 0,0 & 3,2 & 2,0 \\
\hline Pastagem e Forragicultura & 7,9 & 3,9 & 6,8 & 7,4 & 2,2 & 2,0 \\
\hline Avaliação e Conservação de Forragens & 8,5 & 7,8 & 7,4 & 0,0 & 3,2 & 8,0 \\
\hline Sub-total & 21,7 & 21,5 & 21,2 & 7,4 & 15,1 & 18,0 \\
\hline \multicolumn{7}{|l|}{ Produção Animal } \\
\hline Instalações para Produção Animal & 0,0 & 0,0 & 0,3 & 0,0 & 0,0 & 2,0 \\
\hline Manejo de Animais & 5,8 & 4,6 & 3,5 & 7,4 & 5,4 & 0,0 \\
\hline Criação de Animais & 3,7 & 7,8 & 2,9 & 7,4 & 2,2 & 2,0 \\
\hline Produção Animal & 11,1 & 10,4 & 19,6 & 7,4 & 9,7 & 16,0 \\
\hline Sub-total & 20,6 & 22,8 & 26,4 & 22,2 & 17,2 & 20,0 \\
\hline Ecologia dos Animais Domésticos e Etologia & 4,8 & 3,6 & 1,9 & 14,8 & $\mathbf{0 , 0}$ & $\mathbf{0 , 0}$ \\
\hline Genética e Melhor. Dos Animais Domésticos & 13,8 & 14,0 & 14,5 & 22,2 & 18,3 & 16,0 \\
\hline Total Geral & 100 & 100 & 100 & 100 & 100 & 100 \\
\hline
\end{tabular}

(๑) 2007 Sociedade Brasileira de Zootecnia 
decrescentes no período, a ponto de em 2006 não ter nenhum projeto apoiado.

Por outro lado, Produção Animal tem apresentado valores crescentes de solicitação e aprovação, mostrando a pungência dessa subárea.

\section{Considerações finais}

- Houve forte relação entre a demanda bruta (número de propostas submetidas) e a demanda atendida (propostas que receberam financiamento) para as diferentes subáreas do Programa Básico de Zootecnia, principalmente nos julgamentos de bolsas Pq.

- Observa-se que os critérios utilizados pelo Comitê Assessor de Zootecnia para o julgamento das propostas de bolsas $\mathrm{Pq}$ e do Edital Universal levam em consideração substancialmente o Curriculum vitae do proponente e a qualidade dos projetos de pesquisa e não a subárea do conhecimento da proposta.

- Os critérios de julgamento das bolsas Pq e dos Editais Universais são elaborados pelos Comitês Assessores. No caso das bolsas Pq, estes são criados a cada três anos, podendo, excepcionalmente, serem revistos. No caso dos Editais Universais, os critérios são estabelecidos imediatamente antes de cada reunião de julgamento e não são necessariamente os mesmos adotados para as bolsas Pq.

- O CNPq não tem poupado esforços para disponibilizar mais recursos para o investimento em C\&T para melhorar o processo de julgamento e avaliação de suas diferentes ações e para dar publicidade às mesmas, ampliando a interação com a sociedade civil interessada. 